\title{
GESTÃO DE PROJETOS DE PEQUENO PORTE: A ELIMINAÇÃO DE DESPESAS DE EXERCÍCIOS ANTERIORES DE PESSOAL EM UMA ORGANIZAÇÃO MILITAR
}

\author{
SMALL PROJECT MANAGEMENT: ELIMINATION OF EXPENSES FROM \\ PREVIOUS PERSONNEL EXERCISE IN A MILITARY ORGANIZATION
}

Julio Cezar Rodrigues Eloi Exército Brasileiro misterjulio@gmail.com

Rosária de Fátima Segger Macri Russo Doutora em Administração - FEA/ USP romacrirusso@gmail.com

Resumo: O presente relato técnico trata de uma experiência ocorrida em um Setor de Pagamento de Pessoal de uma Organização Militar, no ano de 2019, oportunidade em que foram analisados cerca de 100 processos de despesas de exercícios anteriores. Em virtude de tal demanda incomum, o comando da Unidade adotou algumas medidas com o intuito de sanar tais óbices que impactavam inúmeros militares no período em tela. A principal medida foi capacitar servidores para o processamento dos requerimentos e evitar a ocorrência de novas solicitações intempestivas. Este trabalho objetivou analisar as medidas adotadas frente ao problema em questão, incorporando o tema da aprendizagem organizacional e a gestão de projetos no âmbito de um setor de pagamento de pessoal militar. O trabalho utilizou o método da pesquisa-ação na intervenção realizada em uma Organização Militar do Exército. O resultado mais relevante obtido foi uma sensível diminuição no número de processos no ano seguinte ao projeto de combate ao impasse administrativo elencado. A conclusão destacou que a capacitação de pessoal, o engajamento das partes interessadas e a comunicação refletem positivamente na redução de problemas administrativos.

Palavras-chave: Gestão de projetos. Aprendizagem organizacional. Gestão pública.

Abstract: This technical report deals with an experience that took place in a Military Organization in 2019, an opportunity in which about one hundred expense processes from previous years were analyzed. Due to such high demand, the unit's command adopted some measures in order to remedy such obstacles that impacted countless military personnel during the period in question. One of the measures was the training of civil servants in order to process such requirements and prevent the occurrence of new untimely requests. The objective of this work was to analyze the measures adopted in face of the problem in question, incorporating the theme of organizational learning and project management within a sector of payment of military personnel. The work used the methods of action research in the intervenction that took place in a Military Organization of the Brazilian Army. The main result obtained was a significant decrease in the number of cases in the year following the project to combat administrative obstacles. The conclusion highlighted that staff training, stakeholder engagement and the communication reflects positively on reduction of administrative problems.

Keywords: Project management. Organizational learning. Public management.

\section{Cite como}

American Psychological Association (APA)

Eloi, J. C. R., \& Russo, R. F. S. M. (2021, jul./dez.). Gestão de projetos de pequeno porte: a eliminação de despesas de exercícios anteriores de pessoal em uma organização militar. Revista Inovação, Projetos $e$ Tecnologias - IPTEC, São Paulo, 9(2), 168-183. https://doi.org/10.5585/iptec.v9i2.19155. 


\section{Introdução}

A administração pública é regida por princípios, dos quais, um deles, é o da eficiência, contido no caput do artigo 37 da Constituição Federal (Brasil, 1988). Tal princípio, com o objetivo de melhorar a gestão pública, atribui, aos servidores, a obrigação de trabalhar pelo bem comum com os melhores efeitos para a sociedade. No caso deste relato técnico, versar-se-á sobre a melhoria na rotina de pagamento de pessoal militar com o apoio do projeto de pequeno porte e a aprendizagem no âmbito de uma Organização Militar [OM] do Exército Brasileiro [EB].

O caso concreto tem a sua origem na Divisão de Pessoal, a $1^{\text {a }}$ Seção [1 $\left.1^{\mathrm{a}} \mathrm{Seç}\right]$, a qual incorpora uma subdivisão com a tarefa de atender às demandas pecuniárias dos seus servidores, incumbência do Setor de Pagamento de Pessoal [SPP]. O SPP trabalha com a operacionalização da remuneração de 425 militares e civis, nos direitos pecuniários mais variados, como o adicional de férias, inclusão/exclusão de dependentes econômicos, cadastros de beneficiários do Fundo de Saúde do Exército [FUSEx], salário-família, auxílio-natalidade, assistência préescolar, compensação pecuniária, auxílio-transporte, etapas de alimentação, gratificação de representação, pensões judiciais/extrajudiciais, adicional de habilitação, etc., processados mensalmente por uma equipe de cinco servidores.

Dado um atraso nas solicitações de saque de algumas verbas, mais notadamente a gratificação de representação, etapas de alimentação, auxílio-natalidade, auxílio-transporte e a majoração do adicional de habilitação, cerca de 100 processos de pagamento de despesas de exercícios anteriores deram entrada nesse SPP, entre 2017 e 2018. Na definição da legislação vigente, as despesas de exercícios anteriores "constituem obrigações de pagamento referentes a exercícios já encerrados, atendidas com recursos do exercício financeiro corrente”, nos termos da Portaria Ministerial no 1.054, de 11 de dezembro de 1997 (Exército Brasileiro [EB], 1997). O estoque exacerbado de processos relacionados a exercícios findos criou um óbice administrativo que, somado a outras necessidades de projetos, mais comumente relacionados à infraestrutura física da Unidade, como reformas de pavilhões, alojamentos e refeitórios, construções de instalações logísticas e outros, proporcionou a inclusão de mais um projeto a ser gerenciado com o suporte do núcleo experimental do Escritório de Projetos, tendo seus prazos incluídos no biênio 2019-2020, monitorados através do Software de Gerenciamento de Projetos [GPEx] (EB, 2015).

Dessa forma, este trabalho pretende contribuir com a discussão do assunto no âmbito da administração pública, mais precisamente no Exército Brasileiro, sob à ótica da unidade de 
análise que é o projeto de pequeno porte, gerenciado e executado por assessoria interna, cujo objetivo, neste relatório técnico, é o de analisar as medidas adotadas na eliminação das despesas de exercícios anteriores de pessoal, a contar do seguinte questionamento: como solucionar os processos de pagamentos de despesas de exercícios anteriores de pessoal a partir da gestão de projetos e a aprendizagem organizacional?

\section{Referencial teórico}

Conforme Malmegrim (2014), quando se discute rotinas, ou seja, ações que tenham caráter permanente ou contínuo, atua-se na administração de processos, ao passo que, ao se trabalhar em atividades que proponham uma ação única, tendo início e término identificados, labuta-se com projetos. O projeto, na definição do Project Management Institute [PMI] (2017) é "um esforço temporário empreendido para criar um produto, serviço ou resultado exclusivo". Desse modo, de acordo com o mesmo documento, o gerenciamento de projetos é "a aplicação de conhecimento, habilidades, ferramentas e técnicas às atividades do projeto a fim de atender aos seus requisitos". Na visão de Viana (2012), o projeto é uma ferramenta gerencial para otimizar as atividades, sejam elas estratégicas ou operacionais. É bem verdade que a disciplina é de sistematização recente, por volta de 1950, todavia, desde a antiguidade, há inúmeros exemplos de projetos, sejam da esfera pública ou privada, diversos empreendimentos foram lançados - obras de infraestrutura, ações militares, inovações tecnológicas, dentre tantos outros exemplos.

No caso em tela, a intervenção qualifica-se como um projeto de pequeno porte, vinculado à melhoria da administração interna da Unidade Castrense, com classificação compatível a essa delimitação que, em pouco mais de $65 \%$ dos portfólios das organizações militares, possui custo equivalente ou inferior a 150 mil reais (Rezende, 2015) e, complementado na abordagem de Rowe (2006), pode ser resumido da seguinte maneira:

a) Duração: até seis meses e com regime de trabalho parcial;

b) Equipe: até 10 membros; e

c) Custo: até 65 mil dólares.

No ambiente castrense, os projetos mais simples, aqueles que não guardam complexidades nas etapas de iniciação e planejamento, por sua vez, podem ser gerenciados com o auxílio da ferramenta "5W2H", segundo visualiza-se nas Normas para Elaboração, Gerenciamento e Acompanhamento de Projetos no Exército Brasileiro [NEGAPEB] (EB, 2013). O Exército Brasileiro, em relação à administração de projetos, proporciona às suas 
organizações militares subordinadas, o Sistema de Gerenciamento de Projetos do Exército [GPEx] $(E B, 2015)$, importante ferramenta de acompanhamento de projetos referentes à administração militar (Costa, 2019).

Carvalho e Rabechini (2011) explicam que o gerenciamento de projetos, em seu conjunto de conhecimentos, congrega uma série de capacitações e competências, de interesse dos envolvidos em projetos de diversos tipos. Na seara delineada pelas capacitações, o indivíduo se prepara, não somente para atuar em projetos, mas também em outras atividades da vida humana, como o trabalho e demais rotinas do cotidiano. Na aquisição de novas competências no rol de ações que compõem a existência humana, é natural ancorar novas informações a conceitos anteriormente estruturados (Paula \& Bida, 2008), ao tratar da teoria da aprendizagem significativa, proposta pelo psiquiatra norte-americano David Ausubel, em 1976.

Ademais, deve-se entender que a aquisição e o desenvolvimento de novas competências relacionadas aos projetos dependem da aprendizagem, segundo a forma experiencial apresentada por Kolb (1984), deriva da aprendizagem atual, incorporando a experiência do indivíduo. Com a ideia do referido autor, ressalta-se que não é qualquer experiência que gera a aprendizagem experiencial. A aprendizagem experiencial requer reflexão, motivada, oriunda de aplicação.

No contexto das organizações, a aprendizagem, em determinadas situações, teve os sinônimos de adaptação e mudança, utilizadas no processo em que as entidades se ajustam ao ambiente, consoante Fiol e Lyles (1985). Para as autoras, a aprendizagem advém do conhecimento e associações com ações passadas e desenvolvimento de "insights", ao passo que a adaptação consiste na habilidade em se fazer ajustes como resultado de mudanças em um determinado ambiente ou estrutura. Formalmente, a aprendizagem ocorre, nas organizações, por cursos, treinamentos e palestras, explanam Caldeira e Godoy (2011), que também orientam a respeito da aprendizagem informal, atinente à revisão de práticas e comportamentos para adequação às novas condições nas organizações.

\section{Método da produção técnica}

O trabalho é de natureza qualitativa, incorporando o método da pesquisa-ação e a análise documental, haja vista o pesquisador ter atuado de forma direta na intervenção adotada no projeto em questão e necessariamente haver-se debruçado sobre legislações, pareceres jurídicos e manuais relativos ao tema, os quais não receberam um tratamento analítico, como relatórios, memorandos e base de dados interna (Gil, 2002). A pesquisa-ação permite combinar a teoria e 
a prática com a intervenção do pesquisador na própria organização pesquisada, incorporando a solução do problema relatado e o conhecimento gerado no trabalho científico, conforme explica Oliveira (2011). No mesmo viés, Vergara (1998) assegura que a pesquisa-ação é um tipo de pesquisa participante de cunho intervencionista.

Picheth, Cassandre e Thiollent (2016) ensinam que a pesquisa-ação não prevê unicamente a participação dos pesquisadores, e sim daqueles indivíduos que foram pesquisados no âmbito da intervenção realizada na organização. Thiollent (2009) complementa, ainda, com a forma cooperativa na resolução de um problema coletivo. Sendo assim, tal método é mostrado como um ciclo no qual a prática é aperfeiçoada entre a ação e a pesquisa relacionada, no formato do protocolo estabelecido por Biancolino, Kniess, Maccari e Rabechini Jr. (2012).

$\mathrm{Na}$ intervenção realizada no projeto dos pagamentos de despesas de exercícios encerrados, a aprendizagem orientada para a auditoria e processamento dos tais procedimentos administrativos requereu a capacitação não somente dos agentes envolvidos no pagamento, incluso nesta parte o pesquisador, como também dos pesquisados, servidores da União beneficiados com a aprendizagem na montagem dos processos de interesse, de maneira que o pesquisador, pela participação direta, teve a maior aderência aos eventos relacionados à gestão de projetos, tais quais: o monitoramento e o controle do cronograma, além de administrar as comunicações concernentes às diversas tarefas referenciadas.

No levantamento de dados para este artigo de natureza técnica, para alinhar as variáveis de gestão de projetos de pequeno porte e a aprendizagem organizacional, a pesquisa-ação envolveu a investigação de normas, incorporando a participação e a observação dos fatos que interferiram no aumento do estoque de processos de exercícios anteriores, diretriz de iniciação do projeto, aprovação da autoridade patrocinadora, engajamento das partes interessadas (stakeholders), a capacitação dos efetivos pelo Programa de Aplicação e Conservação de Padrões [PACP] e simpósio de administração, análise dos processos de pessoal frente à legislação vigente, monitoramento das comunicações, execução dos pagamentos dos direitos remuneratórios e avaliação dos resultados. Visando organizar as atividades de investigação (Alyrio, 2009), as tarefas de pesquisa-ação e análise documental deste relatório cumpriram a seguinte sequência: 


\section{Figura 1.}

Atividades de Investigação

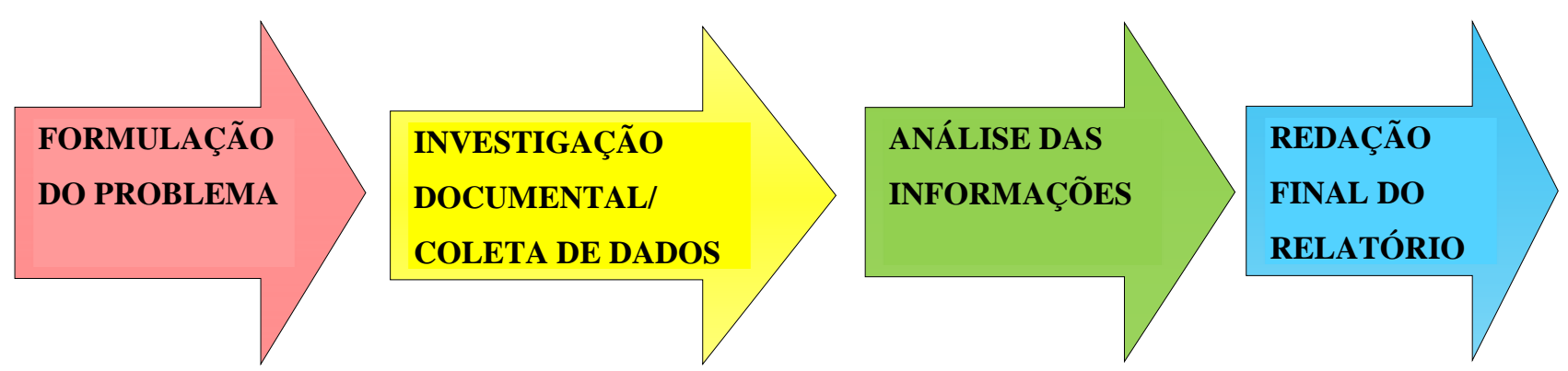

Fonte: Elaborado pelos autores.

\section{Contexto do projeto ou situação-problema}

A ineficiência entre a percepção de alguns direitos remuneratórios e o processamento dos pagamentos dessas verbas no exercício corrente, em especial no que se refere aos militares envolvidos em tarefas externas e missões de suprimento distantes da sede da Organização Militar, a exemplo, o apoio aos refugiados venezuelanos na faixa da fronteira norte do país, acrescidos a exercícios militares na Amazônia e região Sul, demandas administrativas intempestivas sobrecarregaram o setor de pessoal, acabando por necessitar de um projeto para a solução do óbice relatado. Em razão do significativo lapso temporal entre a publicação dos direitos remuneratórios, etapas de alimentação e gratificação de representação, os requerimentos, as análises e os pagamentos desses e de outras verbas, como a majoração do adicional de habilitação, adicional de férias, auxílio-natalidade, etc., contribuíram para o gargalo administrativo, podendo encaminhar para um contexto em que parte dos servidores demandaria o ingresso com pedidos judiciais para a solução de tal impasse.

O Exército Brasileiro, ciente da importância da gestão de projetos em prol da melhor efetividade na esfera pública federal, desde a entrada em vigor da Portaria $n^{\circ}$ 134-EME, de 10 de setembro de 2012, implantou o seu Escritório de Projetos [EPEx], órgão multiplicador do conhecimento da matéria na Força Terrestre. Com efeito, as NEGAPEB, objetos da Portaria $n^{\circ}$ 176-EME, de 29 de agosto de 2013, são um dos mais importantes documentos destinados a promover a cultura de gerenciamento de projetos no âmbito militar. A organização analisada, com a finalidade de aprimorar a gestão interna, criou o Núcleo Experimental do Escritório de Projetos [Nu Exp Escr Proj], adotando as NEGAPEB como regulamento para as suas ações, as boas práticas do Project Management Body of Knowledge [PMBoK®] (PMI, 2017) e as lições aprendidas de outras organizações militares de parâmetros para a gestão dos seus projetos, como forma de estimular a aprendizagem no contexto da própria entidade. 


\subsection{Caracterização da organização}

A organização abordada neste relato técnico é caracterizada como de natureza estatal, de capital público federal, cujo setor de atividade é a defesa nacional, contendo 425 servidores ocupando a sua sede, instalada em 1932. Em relação à Gestão de Projetos, desde 2019, a entidade possui um Núcleo Experimental do Escritório de Projetos, diretamente subordinado ao Comandante e Ordenador de Despesas da Unidade.

\subsection{Caracterização do projeto/problema analisado}

Em 2019, o primeiro ano de mandato do novo Comandante, foi proposto o projeto de melhoria no Setor de Pessoal, com a denominação de Eliminação dos Processos de Despesas de Exercícios Anteriores de Pessoal, no exercício financeiro de 2019, constante do Objetivo Estratégico de Fortalecimento da Dimensão Humana, que tenciona aperfeiçoar a gestão interna para o bem-estar da tropa do aquartelamento, com o saque das despesas remuneratórias atendendo aos princípios da oportunidade e à eficiência no gasto público.

A justificativa do projeto decorre do fato de que a ocorrência de pagamentos de despesas de exercícios findos não deve ser a rotina no serviço público. A regra é atender o princípio da oportunidade na gestão dos recursos financeiros. A existência de tais processos de pagamentos de exercícios passados origina prejuízos de tempo e recursos financeiros para a instituição, e desmotivação dos detentores dos direitos materializados, podendo arranhar a boa imagem da Força Terrestre caso essas demandas evoluam para a esfera judicial. Identificados problemas de capacitação de servidores no processamento de despesas de exercícios anteriores, ademais de comunicação deficiente entre as partes interessadas, tal gargalo exigiu um plano de ação em benefício dos militares de quem os direitos remuneratórios foram reconhecidos e não solucionados no exercício corrente.

Para atacar o revés administrativo supracitado, designou-se um gerente para o projeto, aproveitando a capacitação em curso de curta duração na modalidade à distância em Gestão de Projetos, pela Escola Nacional de Administração Pública [ENAP], e especialização em Gestão Pública, pela Universidade Federal de São Paulo [UNIFESP], sob supervisão direta da autoridade patrocinadora, o Ordenador de Despesas [OD], cujos conhecimentos da matéria decorrem da especialização em Gestão, pela Escola de Instrução Especializada [EsIE], e o Curso de Comando e Estado-Maior, a cargo da Escola de Comando e Estado-Maior do Exército [ECEME]. Os projetos na OM são acompanhados de modo geral pelo Chefe do Núcleo 
Experimental do Escritório de Projetos da Organização Militar [Nu Exp Escr Proj/OM], Mestre em Ciências, pela Universidade Estadual de Londrina [UEL], e responsável pela promoção da cultura de gerenciamento de projetos no órgão, realizando intercâmbio de conhecimento em diversos quartéis no Brasil.

\section{Tipo de intervenção e mecanismos adotados}

Assessoria interna em Gestão de Projetos, na figura do núcleo experimental do Escritório de Projetos da Organização Militar, com a execução das tarefas por parte do Gerente de Projetos, delegadas pela Autoridade Patrocinadora, que identificou as causas e a possível solução para o óbice administrativo, a oportunidade de melhoria, com o auxílio da matriz "5W2H":

a) O que será realizado (WHAT)? Eliminação dos cerca de 100 processos de pagamento de despesas de exercícios anteriores de pessoal;

b) Quem $(W H O)$ ? Setor de Pagamento de Pessoal e Gerente do Projeto;

c) Onde (WHERE)? Unidade militar estudada;

d) Quando $(W H E N)$ ? Da terceira semana de abril a terceira semana de setembro de 2019;

e) Por quê $(W H Y)$ ? São despesas de exercícios passados, comprovadas em Boletins Internos [BI], que não foram quitadas na oportunidade, as quais podem evoluir para ações judiciais caso não sejam solucionadas internamente, de maneira satisfatória para o efetivo das partes interessadas;

f) Como $(H O W)$ ? Capacitando e aperfeiçoando a comunicação e o engajamento entre as partes interessadas no que tange os direitos remuneratórios, além de tornar a equipe do Setor de Pagamento apta a processar os pedidos em tempo hábil, evitando o prolongamento das demandas por tempo incerto. O acompanhamento das tarefas do projeto foi realizado pelo registro dos eventos no programa gerencial GPEx (EB, 2015), a cargo do núcleo do Escritório de Projetos existente na OM desde 2019; e

g) Despesas (HOW MANY)? A cargo do orçamento de custeio à disposição do Ministério da Defesa [MD], destinado ao pessoal militar da ativa alocado no Comando do Exército.

No ambiente castrense, denomina-se, cotidianamente, projetos simples aqueles que não exigem a contratação de especialistas externos à organização, podendo partir de ações pouco complexas para solucionar uma necessidade imediata ou aproveitamento de uma determinada 
oportunidade que foi identificada em diagnóstico pelo Comando ou o Estado-Maior da Unidade. Esses procedimentos que não requerem esforço técnico exacerbado, sendo precedidos do posicionamento do Comandante da Organização Militar, que é a Autoridade Patrocinadora do Projeto [AP], ou sponsor, e quem determina o Estudo de Viabilidade [EV] e aprova o Termo de Abertura do Projeto [TAP] que, no Exército, é conhecido por Diretriz de Implantação do Projeto (EB, 2013).

A título de resumo, os projetos simples, no Exército, são aqueles que não exigem, em sua rotina, equipes multidisciplinares. O cronograma deve iniciar e concluir os trabalhos no mandato de um Comandante, Chefe ou Diretor de Organização Militar [Cmt, Ch, Dir OM]; e não demandam a contratação de empresa ou consultoria externa para entrega integral ou parcial do escopo. A execução desses projetos simples, em geral, é atribuída a um dos subordinados do comandante. Por conseguinte, em tais projetos simples, esse subordinado é designado como o Gerente do Projeto, tendo por documentação básica:
a) Estudo de Viabilidade;
b) Diretriz de Implantação ou Termo de Abertura;
c) Declaração do Escopo;
d) Estrutura Analítica do Projeto;
e) Cronograma; e
f) Plano de Gerenciamento de Custos.

\section{Resultados obtidos e análise}

No projeto em questão, propôs-se que a solução englobaria o relacionamento de duas variáveis: a gestão de projetos e a aprendizagem organizacional. $\mathrm{O}$ gerenciamento do projeto foi estabelecido com a intervenção direta no órgão, tendo início e término definidos em 2019, em um projeto de pequeno porte, dotado de procedimentos simples estipulados nas NEGAPEB (EB, 2013), Manual Interno do Exército, uso da ferramenta gerencial " $5 \mathrm{~W} 2 \mathrm{H}$ " e registro das fases do projeto no software GPEx, no primeiro ano do mandato da Autoridade Patrocinadora, o Comandante da OM, que designou o Gerente do Projeto como o indivíduo diretamente envolvido nas atividades de execução e administração, em razão do escopo do empreendimento relacionado à correção de um entrave administrativo. Acerca da aprendizagem organizacional, buscou-se, na bibliografia de gestão, estudar as barreiras e incentivos existentes nas organizações que interferem na capacitação necessária à solução dos problemas. Verificou-se por limites à aprendizagem, anteriormente, a carência de "fóruns de aprendizagem" e 
"mecanismos de comunicação interna" (Schaw, 1994, como citado em Bastos, Gondim e Loiola, 2004, p. 226). Caldeira e Godoy (2011) também concordam que as barreiras de comunicação funcionam limitando a aprendizagem organizacional. Em relação aos incentivos, identificou-se que, no projeto, houve o forte interesse das partes na adoção de medidas corretivas, semelhante ao explicado por Caldeira e Godoy (2011).

A fim de responder à formulação do projeto, foi necessária a capacitação conjunta dos servidores, para que os mesmos pudessem compreender a sistemática de remuneratória no Exército, ignorada por muitos. À vista disso, no calendário de capacitação do quartel, incorporaram-se instruções de proventos para todo o efetivo, nas sessões integrantes do Programa de Aplicação e Conservação de Padrões e Simpósio de Administração, oportunidades em que foram apresentados resumos em forma de fluxograma:

\section{Figura 2.}

\section{Fluxograma}

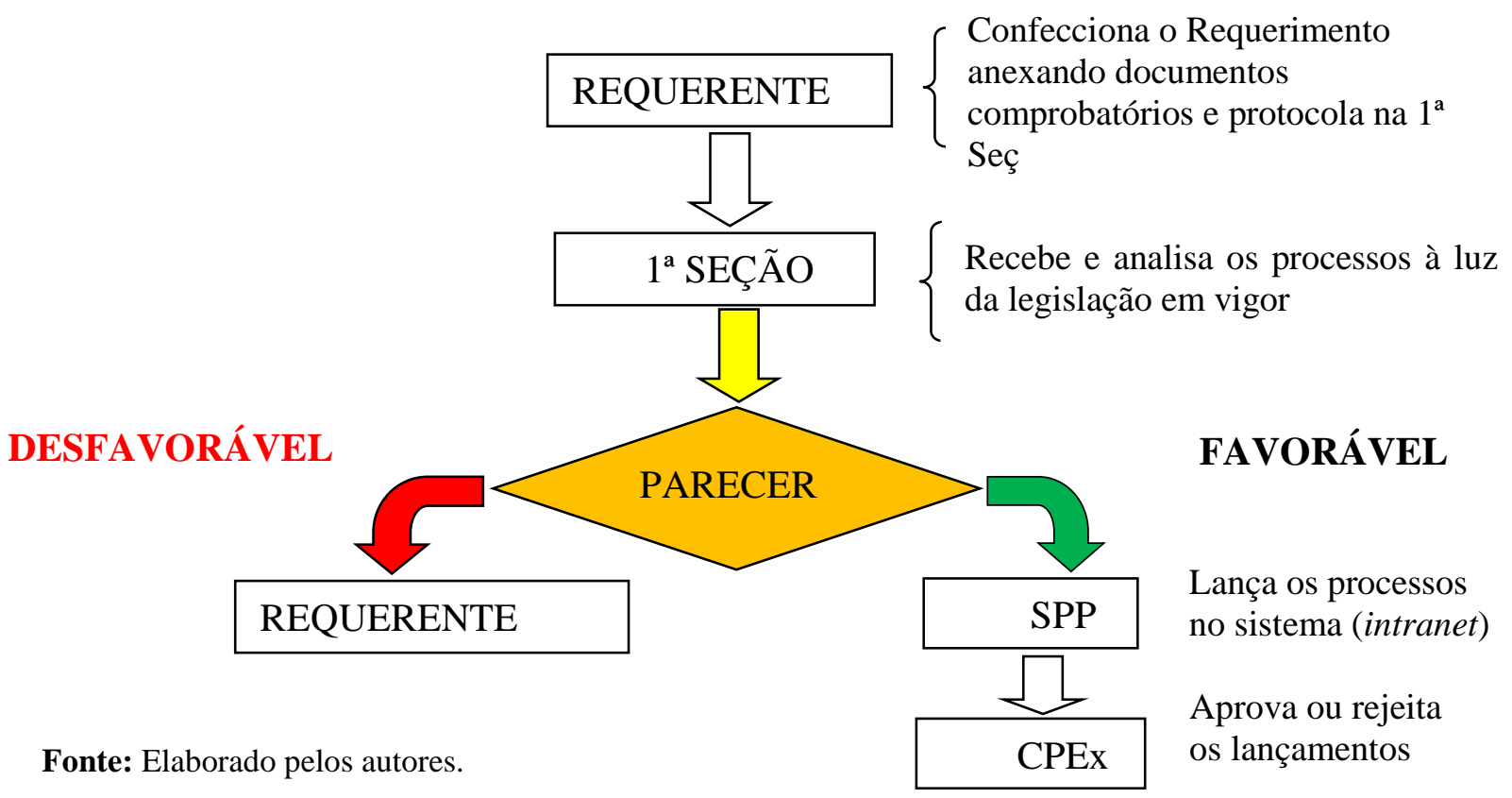

Nesse sentido, a liderança, nos pequenos níveis, foi estimulada com vistas a facilitar a comunicação dos problemas de pagamento de pessoal junto aos interessados, distribuídos em frações como seções e pelotões, objetivando combater a origem do problema, comprometendo a organização a aprender o funcionamento dos processos de modo integrado. Cabe enfatizer que, em 2018, houve a tentativa de solucionar integralmente tais óbices administrativos na OM, sendo lançados 51 processos, dos quais apenas dois foram aprovados pelo Centro de Pagamento do Exército [CPEx], o que comprovou o baixo nível de capacitação dos servidores envolvidos 
e a frustração dos interessados. Em 2019, após a devida capacitação do Gerente do Projeto por curso promovido pelo Instituto de Economia e Finanças do Exército [IEFEx], palestras sobre pagamento de pessoal com todo o efetivo, além de diversas reuniões de capacitação administrativa e intercâmbio com outros quartéis envolvidos na eliminação dos processos de pagamento de despesas de exercícios anteriores, foram lançados 99 processos, dos quais 94 foram aprovados pelo CPEx, comprovando a correlação positiva que a capacitação de pessoal, engajamento entre as partes interessadas, apoio irrestrito da chefia e a comunicação eficiente, encaminharam para a significativa melhoria no projeto de eliminação dos processos de pagamentos de despesas de exercícios anteriores concernentes às verbas remuneratórias do pessoal militar. A experiência anterior malsucedida, em 2018, e o feedback dos agentes envolvidos foram doloridas lições aprendidas, contudo, importantes no ritmo da aprendizagem (Bastos et al., 2004).

A tabela a seguir ilustra os ganhos advindos do relacionamento que um projeto simples, porém bem delimitado, apoiado decisivamente pelo Comando da Unidade, focado no bem-estar do efetivo, aliado à aprendizagem das partes interessadas (stakeholders) e a comunicação eficiente, facilitou de sobremaneira o atingimento dos resultados:

\section{Tabela 1.}

Despesas de Exercícios Anteriores Pagas em 2018 e 2019

\begin{tabular}{|c|c|c|c|}
\hline Período & Quantidade de processos & Processos aprovados & Taxa de sucesso \\
\hline 2018 & 51 & 2 & $4 \%$ \\
\hline 2019 & 99 & 94 & $96 \%$ \\
\hline
\end{tabular}

Fonte: Elaborado pelos autores.

Deve-se, ainda, acrescentar que a eliminação dos processos de pagamentos de despesas de exercícios anteriores trouxe a diminuição de retrabalho, pois a análise de requisições de verbas de exercícios passados é um processo meticuloso comparado a um tipo de sindicância que demanda tempo extra para apuração de direitos remuneratórios, conferência de diversos amparos legais, assim como a espera do interessado na expectativa do benefício remuneratório, requerido antes da prescrição quinquenal (Decreto $n^{\circ}$ 20.910, de 06 de janeiro de 1932).

$\mathrm{Na}$ Unidade de análise, o projeto de pequeno porte em uma organização do serviço público federal possibilitou comprovar, de forma indubitável, o positivo nexo causal do efetivo gerenciamento de projetos com o estímulo à aprendizagem organizacional, cuja experiência não teve a intenção de esgotar o assunto. Outrossim, propõe que, na administração pública, o 
gerenciamento de projetos é uma prática interessante para o exercício da liderança nos pequenos níveis, tornando-se imprescindível buscar eliminar as barreiras à aprendizagem, criando fóruns de aprendizagem e comunicação, estimulando as atitudes corretivas por força das partes interessadas, projetando a melhoria do ambiente organizacional, que facilitarão, à organização, receber os benefícios do projeto, traduzidos no cumprimento do escopo, cronograma e custo.

\section{Conclusão}

Ao longo das páginas deste relato técnico, foi possível relacionar, de forma positiva, a experiência da gestão de um projeto de pequeno porte em uma organização militar do Exército Brasileiro com a aprendizagem organizacional. Nitidamente, observou-se que, em 2018, o resultado foi abaixo do esperado quando comparado ao exercício financeiro de 2019 , no que se referiu à solução dos processos de pagamentos de despesas de exercícios anteriores. O projeto de pequeno porte, que embora não exigisse complexidade e inovações tecnológicas para a eliminação das barreiras à aprendizagem e solução dos óbices administrativos, demandou certo planejamento e capacitação dos stakeholders internos na solução dos problemas administrativos, ademais do apoio fundamental que a autoridade patrocinadora exerceu durante os trabalhos.

O Exército Brasileiro implantou o seu Escritório de Projetos, o EPEx, a fim de administrar o seu portfólio estratégico e ter uma organização referência para a multiplicação do conhecimento no âmbito da Força Terrestre, tornando possível realizar o intercâmbio com as demais Forças Armadas e o Ministério da Defesa. No caso em discussão, gerenciou-se um projeto de simples complexidade com o auxílio do manual proposto pelo próprio Exército, as NEGAPEB (EB, 2013), que orientou os trabalhos para a ferramenta gerencial "5W2H", com o monitoramento pelo sistema de gerenciamento de projetos da instituição, o GPEx (EB, 2015).

Como qualquer órgão hierarquizado, a organização estudada neste relato técnico possuiu barreiras à aprendizagem que, em 2018, decorriam da ausência de fóruns de aprendizagem e poucos mecanismos de comunicação interna. Formalmente, em 2019, o órgão incentivou a aprendizagem organizacional, apoiando as atitudes corretivas das partes interessadas, num ambiente de sã camaradagem, em sessões de instrução no contexto do PACP e simpósio de administração, com o propósito de que as dúvidas relacionadas aos direitos remuneratórios fossem dirimidas efetivamente e o SPP fosse eficientemente capaz de operacionalizar os proventos da tropa de forma a atender os princípios da eficiência e da oportunidade. Salienta-se que o próprio gerente do projeto foi capacitado na tarefa de 
pagamento de pessoal, unindo o conhecimento tácito ao explícito na área. $\mathrm{O}$ trabalho demonstrou, mais uma vez, que o engajamento dos stakeholders internos e o apoio da autoridade patrocinadora, o sponsor, contribuem positivamente para o sucesso do projeto, traduzidos no cumprimento do triângulo de ferro do projeto (custo, tempo e escopo), cabendo às lideranças papel fundamental na promoção de um ambiente que incentive à aprendizagem organizacional.

O estudo se pautou pelo caso de uma Organização Militar do Exército Brasileiro, localizada na capital paulista, com realidade distinta de outras instituições similares ao longo do território nacional, logo, é prudente que generalizações não devam ser replicadas sem o devido estudo de situação que leve em conta a realidade de cada entidade. No entanto, há muitas considerações que podem ser aproveitadas, a exemplo da saudável relação entre a aprendizagem e a gestão de projetos no cotidiano das organizações.

Como limitação dos trabalhos, entende-se que estudos futuros na administração pública possam incorporar a análise das competências, soft e hard skills, no âmbito da gestão de projetos no serviço público. Rabechini, Carvalho, Rodrigues e Sbragia. (2011) apresentam relevante estudo a respeito das competências individuais, de equipe e da organização. O Exército Brasileiro, por exemplo, sendo uma corporação de capilaridade nacional, dado os inúmeros projetos que gerencia, é um terreno fértil para estudos nesse seguimento, portanto, outras metodologias de gerenciamento de projetos, como as de projetos ágeis e híbridos, são sugestões de novas formas de administrar os projetos, sejam eles de pequeno, médio e grande porte, sob novos prismas gerenciais.

E, para finalizar, há que se compreender determinadas especificidades que são encontradas no gerenciamento de projetos nas organizações do setor público em relação às práticas encontradas na iniciativa privada, dado o fato que, na gestão pública, estão envolvidos aspectos sociais que se sobrepõem à lucratividade buscada na concorrência das corporações privadas, além da burocracia e controle específicos no cotidiano estatal (Kreutz \& Vieira, 2018).

\section{Referências}

Alyrio, R. D. (2009). Métodos e técnicas de pesquisa em administração. Rio de Janeiro: Fundação CECIERJ. Recuperado em 01 novembro, 2021, de https://canal.cecierj.edu.br/recurso/6448

Bastos, A. V. B., Gondim, S. M. G., \& Loiola, E. (2004). Aprendizagem organizacional versus organizações que aprendem: características e desafios que cercam essas duas abordagens de pesquisa. RAUSP Management Journal, 39(3), 220-230. Recuperado em 01 novembro, 2021, de 
http://www.spell.org.br/documentos/ver/16796/aprendizagem-organizacional-versusorganizacoes-que-aprendem--caracteristicas-e-desafios-que-cercam-essas-duasabordagens-de-pesquisa/i/pt-br

Biancolino, C. A., Kniess, C. T., Maccari, E. A., \& Rabechini Jr., R. (2012). Protocolo para elaboração de relatos de produção técnica. Revista de Gestão e Projetos, 3(2), 294307. Recuperado em 01 novembro, 2021, de http://www.spell.org.br/documentos/ver/41922/protocolo-para-elaboracao-de-relatosde-producao-tecnica/i/pt-br

Brasil. (1932). Decreto n ${ }^{\circ} 20.910$, de 06 de janeiro de 1932. Regula a prescrição quinqüenal. Recuperado em 01 novembro, 2021, de http://www.planalto.gov.br/ccivil_03/decreto/antigos/d20910.htm

Brasil. (1988). Constituição da República Federativa do Brasil. Brasília: Senado Federal, 1988. Recuperado em 01 novembro, 2021, de http://www.planalto.gov.br/ccivil_03/constituicao/constituicao.htm

Caldeira, A., \& Godoy, A. S. (2011). Barreiras e incentivos à aprendizagem organizacional: um estudo de caso. Revista de Gestão, 18(4), 513-530. Recuperado em 01 novembro, 2021, de http://www.spell.org.br/documentos/ver/7432/barreiras-e-incentivos-aaprendizagem-organizacional--um-estudo-de-caso/i/pt-br

Carvalho, M. M., \& Rabechini, R. (2011). Fundamentos em gestão de projetos: construindo competências para gerenciar projetos (3a ed.). São Paulo: Atlas.

Costa, C. M. (2019). Administração Pública Estratégica: Observação Participante da implementação do Sistema de Gerenciamento de Projetos do Exército em uma Organização Militar. Trabalho de conclusão de curso, Universidade Federal da Integração Latino-Americana, Foz do Iguaçu, PR, Brasil. Recuperado em 01 novembro, 2021, de https://dspace.unila.edu.br/handle/123456789/5502?show=full\&locale-attribute=en

Exército Brasileiro [EB] (1997). Portaria Ministerial no 1054, de 11 de dezembro de 1997. Aprova as normas para o pagamento de despesas de exercícios anteriores no Ministério do Exército. Recuperado em 01 novembro, 2021, de http://www.dgo.eb.mil.br/images/sgs/PortMin1054.pdf

Exército Brasileiro [EB] (2012). Portaria n ${ }^{\circ}$ 134-EME, de 10 de setembro de 2012. Implanta o Escritório de Projetos do Exército - EPEx. Recuperado em 01 novembro, 2021, de http://www.epex.eb.mil.br/images/pdf/P-134-EME-10-09-2012-1.pdf

Exército Brasileiro [EB] (2013). Portaria n 176-EME, de 29 de agosto de 2013. Aprova as normas para elaboração, gerenciamento e acompanhamento de projetos no Exército Brasileiro e dá outras providências. Recuperado em 01 novembro, 2021, de http://www.sgex.eb.mil.br/sistemas/be/copiar.php?codarquivo=1187\&act=bre

Exército Brasileiro [EB] (2015). Portaria nº 204-Cmt Ex, de 17 de março de 2015. Adota o Sistema de Gerência de Projetos do Exército como Software de Apoio ao 
Gerenciamento de Projetos no âmbito do Exército Brasileiro e dá outras providências. Recuperado em 01 novembro, 2021, de http://www.sgex.eb.mil.br/sistemas/be/copiar.php?codarquivo=1345\&act=bre

Fiol, C. M., \& Lyles, M. A. (1985). Organizational Learning. The Academy of Management Review, 10(4), 803-813. Recuperado em 01 novembro, 2021, de https://www.jstor.org/stable/258048?seq=1\#metadata_info_tab_contents

Gil, A. C. (2002). Como elaborar projetos de pesquisa (3a ed.). São Paulo: Atlas.

Kolb, D. (1984). Experiential Learning: experience as the source of learning and development. New Jersey: Prentice Hall.

Kreutz, R. R., \& Vieira, K. M. (2018). A Gestão de Projetos no Setor Público: os desafios de suas especificidades. Gestão Pública: Práticas e Desafios, 9(1), p. 1-20. Recuperado em 01 novembro, 2021, de https://periodicos.ufpe.br/revistas/gestaopublica/article/viewFile/234989/31214

Malmegrim, M. L. (2014). Gestão operacional (3a ed.). Florianópolis: UFSC.

Oliveira, M. F. (2011). Metodologia científica: um manual para a realização de pesquisas em administração. Catalão: UFG.

Paula, G. M. C., \& Bida, G. L. (2008). A importância da aprendizagem significativa. Recuperado em 01 novembro, 2021, de http://www.diaadiaeducacao.pr.gov.br/portals/pde/arquivos/1779-8.pdf

Picheth, S. F., Cassandre, M. P., \& Thiollent, M. J M. (2016). Analisando a pesquisa-ação à luz dos princípios intervencionistas: um olhar comparativo. Educação, 39(Esp), 1-10. Recuperado em 01 novembro, 2021, de https://www.redalyc.org/articulo.oa?id=848/84850103002

Project Management Institute [PMI] (2017). Um guia do conjunto de conhecimentos em Gerenciamento de Projetos (Guia PMBoK®) (6a ed.). Pensilvânia, EUA.

Rabechini, R.; Carvalho, M. M., Rodrigues, I.; \& Sbragia, R. (2011). A organização da atividade de gerenciamento de projetos: os nexos com competências e estrutura. Gestão e Produção, 18(2), 409-424. Recuperado em 01 novembro, 2021, de https://www.scielo.br/scielo.php?script=sci_arttext\&pid=S0104-530X2011000200014

Rezende, L. B. (2015). Gerenciamento de projetos de pequeno porte nas organizações militares do Exército Brasileiro. Giro do Horizonte, 4(1). Recuperado em 01 novembro, 2021, de http://www.ebrevistas.eb.mil.br/GH/article/view/2297/1853

Rowe, S. F. (2006). Project Management for Small Projects. USA: Management Concepts.

Thiollent, M. (2009). Metodologia da Pesquisa-Ação (14a ed.). São Paulo: Cortez.

Vergara, S. C. (1998). Projetos e Relatórios de Pesquisa em Administração (2a ed.). São Paulo: Atlas. 
Viana, C, P. (2012). A gestão de projetos no âmbito da administração pública federal: uma visão estratégica. Anais do Congresso CONSAD de Gestão Pública, Brasília, DF, Brasil, 5. 